\title{
THE EFFECTIVITY OF ORAI APPLICATION IN TEACHING PRESENTATION SKILLS FOR NON-ENGLISH SENIOR HIGH SCHOOL TEACHERS
}

\author{
Cita Mustika Kusumah ${ }^{1}$ Dien Novita ${ }^{2}$ \\ ${ }^{1,2}$ Politeknik LP3I Bandung, Indonesia \\ Email: cita.mustika24@gmail.com¹ dienovita988@gmail.com²
}

First Received: August 2019

Final Proof Received: September 2019

\begin{abstract}
ABTRACT
Non-English teachers often get nervous and are not confident when they have to speak up in English, especially when they have to speak in front of many people or do the public speaking in English. But nowadays, there are many mobile applications that offer the new method in speaking English. Orai is one of the applications which concerns to help the users in improving their English-Speaking Skills. The research aims to examine the improvement of teachers' speaking skills by using Orai application. The data were taken from the teachers who did not teach English in Senior High School in Bandung. Data were analyzed using descriptive statistic by finding out the total score per item. The results of the research show that Orai application helps teachers in improving their speaking skill. It helps teachers in correcting their pronunciation and their intonation when they speak. It also reduces some sources for the efficiency such as books, speakers, writing tools, headset, etc. The participants show the positive and good response using Orai application in assisting participants' speaking fluency.
\end{abstract}

Keywords: Presentation skills, MALL, Orai application

\section{INTRODUCTION}

In this sophisticated era, many new technologies have emerged. Human life is facilitated by the development of new technology today. In addition, many people have used mobile devices for daily needs such as shopping for daily necessities, communicating with relatives or family, and even learning various materials through mobile devices. Mobile devices appear in various forms and vary. Without realizing it, mobile devices also began to take an important role in everyday life. The emergence of mobile devices really changes our way of life such as how to communicate and how to learn something. One example of mobile devices that are widely used is smartphones. On smartphones, there are many applications that can be used to help them doing something. Smartphones are phones that have capabilities such as computers, usually have large screens and the operating system is capable of running common applications (Oxford, 2019). The use of smartphones has recently changed the pattern of people's lives. The function of smartphones is not only a tool for remote communication, but also as a sophisticated tool that can be used for a variety of things by the users. The use of smartphones is also very diverse. Many people use smartphones to play games, open social media, browse, etc., but not many know that using smartphones can be used for learning. Learning using mobile learning (m-learning) allows us to learn wherever and whenever. The concept of language learning with m-learning or commonly referred to mobile-assisted language learning (MALL) is believed to be an ideal solution for language learning in the context of time and place (Miangah \& Nezarat, 2012).

In Indonesia, many people think that learning and practicing English are very difficult because the structure of Indonesian and English is different. In addition, most 
Indonesian people do not believe in speaking English because they are obstructed by accent and regional language dialects they have. They think to overcome the dialect and accent, they must learn directly with the Native Speakers. And to learn English and practice to speak English, they must be in the classroom. So that, there is laziness and unbelief in speaking English. Actually, without being in the room, technology has been very helpful in providing solutions to improve English language skills in a fun way through the m-learning application that can be downloaded on a smartphone. They can open and use it anywhere and anytime at a relatively more affordable cost. Therefore, we realize that the ability to speak English is now very much needed to be able to communicate in the international world. Remembering English is one of the international languages used in the world. But if the community is confronted with the embarrassment of speaking English with a variety of reasons stated, then how we can convey ideas or develop our ideas in international forums. In addition, we also find the same problem in the world of education, especially in the environment of non-English high school teachers where most of them cannot speak English because of various factors. Meanwhile, they must teach English to their students so that their students will be able to communicate well in international forums. At the same time, the Bandung City Government implements the "Thursday English" program which of course must be supported by the ability of teachers to speak English, at least they should be able to practice it every Thursday.

The program in this application can help practicing to speak English independently and they can also see the instant feedback provided by this application. Through teaching using this application, students will be facilitated in the teaching process. This is because this application is fun and easy to understand even students can quickly get their own voice recordings. Another advantage of the Orai application can detect how many fillers we say when we are talking, also able to detect how many words we say.

Answering the problems described above, we are trying to provide a solution by providing training using the ORAI application to non-English high school teachers because we find that non-English high school teachers in Regol Bandung District face the same problems, where they are not confident when you have to speak in English. Also provides new methods in teaching to speak English using the latest technology, flexible, inexpensive and can be carried anywhere easily.

This study reports the results of the research dealing with the application of Orai as follows:

1. What are the results of learning English using the Orai application?

2. What resources can be efficient with the Orai application?

3. How do the participants' respond after using the Orai application for learning English?

\section{General View of Mall Method}

One form of language learning processes that use mobile devices is Mobile-Assisted Language Learning (MALL). MALL is a combination of moving learning processes (mlearning) and language learning processes that are assisted by computers (CALL). Some mobile devices used in the MALL application include: cellular phones (including: iPhone or iPad), MP3 or MP4 players (example: iPod) and Personal Digital Assistants (PDAs) (example: Palm Pilot, Blackberry and others). Through the use of MALL, students are expected to be able to access language learning materials and communicate with their teachers and colleagues anytime, anywhere so students do not need to be in class or at the computer. Based on (Kukulska-Hulme \& Shield, 2007), MALL can be any type of 
language learning using portable devices such as: PDAs, cellphones, smartphones, pads, pods and other handheld devices used for voice calls, making short messages, video chatting, listening MP3, MP4, MPEG audio, web surfing, shopping, electronic dictionaries and others.

Hajim's opinion (Hajim, 2012), states that using mobile devices helps students to have easy access to the information they need. Therefore, this device acts as a supportive educational tool that can improve student performance in the classroom. In addition, cellular learning helps students personalize their learning and they can learn in their own way. The current function of MALL is not only a primary source of language education for students, but also supports retention and utilization of newly acquired language skills. Through cellular participation in training and short assignments, students can maintain their linguistic talents. Some cellular devices according to Trinder are cellphones, PDAs, Smartphones, GPS devices, laptops, MP3 or MP4 players, video tapes, multimedia players (e-organizers, e-books, CDs and DVDs) as cellular learning devices. Despite the efforts made to use these devices in the setting of artificial learning for experimental purposes, it can now be observed that they are also used for educational purposes and many of them have proven to be effective language learning tools. The benefit of MALL is that students can control the learning process and progress at their own pace based on their cognitive conditions in the non-class space environment because students use mobile learning devices. Some outdoor classes that students use for learning, including: in front of their own personal computers online or offline, on a bus / tram / train / vehicle or in a library, outside or at work, at all times and where- where (Geddes, 2004). By looking at the situation, it can be concluded that portability and connectivity are the main special features of cellphones. In terms of portability, this makes it easy for users to be able to use cellphones and bring learning material to anywhere and everywhere. Whereas in terms of connectivity, the device must always be connected to the learning website by using wireless networks in order to access learning materials including short message services and mobile e-mail to transfer information between instructors and students. In addition, the high level of flexibility and low cost, as well as the small size and user friendliness are the advantages of the cellphone.

\section{Orai Application}

The Orai application is an application found on mobile phones created by two students, Danish Dhamani and Paritosh Gupta from Drexel University in Philadelphia. They created this application to help people become more fluent in public speaking and confidence when conducting public speaking through practice and consistent feedback.

Orai is a public speaking application that can provide instant feedback about speeches. The instant feedback given is filler, speed, energy and clarity in speaking. By using this application, users can practice and follow speaking and public speaking skills independently. This application provides training modules in small bite sizes and provides instant feedback. Also, this application provides instructions on how users can use useless filler words. In addition, users can find out if the user talks too often or too fast or even too slowly.

The Orai application will give the results of the transcript when talking and tell how the tone of voice is also the right energy. Users can also enter transcripts owned by users and practice them in different ways.

\section{Teaching Presentation Skill}


Teaching English is the main key in the success of world interaction. The success in mastering this language will facilitate the flow of togetherness of the nation's natar. Therefore, it is important for us to learn and understand language intact. Siahaan (2008: 7) explains that language is one of the human heritages which plays an important role in human life itself, such as in thinking, conveying ideas, and communicating with others. "Language is a unique human inheritance that plays the very important role in human's life, such as in thinking, communicating ideas, and negotiating with the others". Generally, language is used as a tool to communicate. The communication process will run well when the two communicating parties are equipped with knowledge of language and language skills. Mastery of vocabulary and grammar are two aspects that must be mastered by someone who wants to learn a language, especially foreign languages. Meanwhile, to actively communicate, the skills that must be mastered include speaking skills, listening skills, writing skills, and reading skills.

Hardjono Rayner (2001: xxv) argues that English is an international language so it is the most widely used language throughout the world. We can see the position of English as an international language with anglofon speakers (English speakers) spread over five continents. English is not only used by anglofon speakers, but is used by the world community, especially those who tend to be modern. This is also due to the existence of various advantages in English, among others namely in the wealth of its idioms (special expressions), which are more varied and always developing than other European languages. Hardjono Rayner (2001) also mentioned that many good elements of the cultural environment of various languages were absorbed by this language (English). Its influence breaks through all aspects of life; namely in the fields of scientific, political, economic, popular culture, film, to the last breakthrough, namely in the world of the internet.

Mastery of English in this modern era is a must due to the development of the era and the use of English as the language of globalization. In Indonesia, many people think that learning English is difficult because the structure of Indonesian and English is different. Besides that, most of them are not confident when speaking English. Therefore, we realize that English teaching is really needed in Indonesia. We also found this problem in the world of education, especially in non-English high school teachers where they could not speak English due to various factors. At the same time, we would like to provide training in teaching English in a fun way, using applications for non-English high school teachers in Regol District, Bandung. This English-speaking teaching training is to practice speaking English independently and they can practice it with ease and fun. Also provides new methods of teaching English speaking using the latest technology that is more flexible, inexpensive and can be carried anywhere easily

\section{METHOD}

The method of this research will be carried out with experimental methods with the stages of research covering: 1. Quantitative data collection by giving questionnaires and pretests to non-English high school teachers, 2. Analyzing quantitative data based on questionnaire results, 3. Obtaining quantitative results from results questionnaire, 4. Implementation English speaking training for non-English high school teachers without using the application, 5. Testing speaking English speaking with the use of applications, 6. Post-test and questionnaire implementation for non-English high school teachers, 7 Data collection and data analysis after conducting English Language Training using applications, 8. Obtaining data analysis results.

\section{Participants}


The research was held in Nurul Ilmi Lil Ummah Foundation in Regol District, Bandung. The variables observed consisted of English-speaking skills in non-English high school teachers. The model carried out is Field Research where research will be conducted at the Regol Sub-District.

\section{Data Collection Procedures}

The researchers will conduct quantitative data collection by giving questionnaires and pre-tests to non-English high school teachers, followed by analyzing the quantitative data from the questionnaire. The researchers get quantitative results from quantitative data analysis. The researchers will determine the quantitative results that have been analyzed and will be explained in detail. The researchers will provide English speaking training using the Application. After that, a Post-Test was given for collecting and analyzing qualitative data. After the researcher has collected and analyzed qualitative data from the Post-Test and Questionnaire given, the researcher obtained qualitative results. Finally, the researcher will interpret qualitative data and explain the results obtained in detail.

\section{FINDINGS AND DISCUSSION}

Through the research, the writers found out that using Orai application consists of four steps; recording, listening, correcting, and repeating. The steps of the activities are described as follows:

The first step was recording; the participants were recording their utterances. The participants then practiced in uttering the utterance many times. After they were sure about their pronunciation and intonation and confident enough to record their utterances, then they did record. Only the target language was recorded using Orai application.

The second step was listening. After the participants recorded their utterance, the device would take a few second to analyze participants' utterance. The device then would show the result and gave direct feedback to the participants. The feedback covered pronunciation, tone, energy, filler as well as the clarity of the participants' utterance as well as the score of the utterance. The result of the analysis of pronunciation can be seen in the transcript sheet. The participants' result of speaking energy was indicated by the graphic of energy. There were two colors in it; yellow color indicated that participants' speaking was monotonous and purple color indicated the participants' speck energy. The participants' useless filler was also analyzed. At the end, participants were able to get their scores of clarities. The participants also got suggestion from the device. Due to the suggestions, the participants then listened to their recording speech.

The third step was correcting. Having reading the result or the analysis, the participants might make some corrections dealing with the mispronunciation, the tone, the filler, or the energy suggested by the device.

The final step was repeating. Once the participants corrected their utterance, they might do some repetitions in practicing the speech through the recording. As the score increased and they felt comfort with the score they might submit the score to the teacher together with the transcription of the text.

From the research, it also could be described that the participants were very excited in practicing speaking using Orai application. They worked with their friends, communicated their experience without any feeling of fright. By mean of Orai application they got direct feedback of their speech then they got suggestion from the app to fix up their performance.

After they felt confident with their speaking skill, the participants tried to practice the presentation exercises in the correct presentation stages; Opening presentation, Content and Closing presentation. Because of their fear of speaking English, they could 
not even introduce themselves in English. Therefore, they never wanted to do the presentation in English. Having done Orai application, the participants started to be comfortable to speak English in front of people include in doing the English presentation. The following table shows the results of questionnaire that were given to the participants:

Table 1. Participants' responses toward orai application

\begin{tabular}{|c|c|c|c|c|}
\hline No. & Questions & Agree & Disagree & Total of participants \\
\hline 1. & Orai application is easy to be used. & 33 & 7 & 40 \\
\hline 2. & Orai helps me in reducing my fear. & 22 & 18 & 40 \\
\hline 3. & $\begin{array}{l}\text { Orai guides me to fix my intonation when } \\
\text { speaking. }\end{array}$ & 25 & 15 & 40 \\
\hline 4. & Orai controls my speed of speaking. & 30 & 10 & 40 \\
\hline 5. & Orai coaches me on my pace of speech. & 23 & 17 & 40 \\
\hline 6. & Orai coaches me to fewer my filler. & 25 & 15 & 40 \\
\hline 7. & $\begin{array}{l}\text { Orai helps me in practicing my } \\
\text { presentation. }\end{array}$ & 30 & 10 & 40 \\
\hline 8. & I feel comfortable when I practice Orai. & 32 & 8 & 40 \\
\hline 9. & $\begin{array}{l}\text { I feel comfortable in doing presentation } \\
\text { after I practice Orai. }\end{array}$ & 31 & 9 & 40 \\
\hline 10. & $\begin{array}{l}\text { I can practice English anytime by using } \\
\text { Orai. }\end{array}$ & 35 & 5 & 40 \\
\hline & Total & 286 & 114 & 400 \\
\hline & Percentage & $71,5 \%$ & $28,5 \%$ & $100 \%$ \\
\hline
\end{tabular}

Table 1 describes the questionnaire items, number of respondents, questionnaire responses' results. It shows $71,5 \%$ participants agree with the items of the questionnaire and 28,5\% disagree. It means that most of the participants are helped by using Orai application and become confident in speaking English in front of people.

\section{CONCLUSION}

From the research, it can be concluded that Orai application fixes the participants' pronunciation, the participants' filler are disappear, the participants' tone are better and the participants' energy become energetic. There are many sources that can be replaced by using this application for learning presentation skill. The sources are books, pencils, pens and peer partner. By using Orai application, the participants do not need the partner to review their speech result because the application provides the feedback completely such as tones, filler, pace, text and energy. Most of the participants enjoy the process of present something in English and their confidence increase automatically after using the application by themselves. The class situation is more fun and relax compare to studying without application. The students are more enthusiastic to the subject especially when they practice themselves in speaking English by using Orai application.

It is recommended to other teachers or lecturers to conduct the research about this application in any other speaking subjects such as Conversation, Reading aloud and Public speaking. 


\section{REFERENCES}

Hajim, M. (2012). Mobile Learning: 5 Advantages and 5 Disadvantages. Retrieved from http://edudemic.com

Kukulska-Hulme, A., \& Shield, L. (2007). An overview of Mobile Assisted Language Learning: Can mobile devices support collaborative practice in speaking and listening? EuroCALL 2007, 1-20. https://doi.org/10.1017/S0958344008000335

Miangah, T. M., \& Nezarat, A. (2012). Mobile-Assisted Language Learning. International Journal of Distributed and Parallel Systems, 3(1), 309-319. https://doi.org/10.5121/ijdps.2012.3126

Oxford. (2019). Lexico.

https://www.lexico.com/en/definition/smartphone

Retrieved from 